IRA-International Journal of Applied Sciences ISSN 2455-4499; Vol.10, Issue 01 (January 2018)

Pg. no. 1-6

Institute of Research Advances

https://research-advances.org/index.php/IRAJAS

\title{
A Pipetting Sample Preparation with Water Eluent followed by Water Mobile Phase HPLC-DAD Analysis for Residual Monitoring of Sulfadimidine in Milk
}

\author{
Dr. Naoto Furusawa \\ Associate Professor, Graduate School of Human Life Science, Osaka City University, Osaka 558-8585, Japan.
}

Type of Review: Peer Reviewed.

DOI: http://dx.doi.org/10.21013/jas.v10.n1.p1

\section{How to cite this paper:}

Furusawa, N. (2017). A Pipetting Sample Preparation with Water Eluent followed by Water Mobile Phase HPLC-DAD Analysis for Residual Monitoring of Sulfadimidine in Milk. IRA International Journal of Applied Sciences (ISSN 2455-4499), 10(1), 1-6. doi:http://dx.doi.org/10.21013/jas.v10.n1.p1

(C) Institute of Research Advances.

\section{(cc) BY-NC}

This work is licensed under a Creative Commons Attribution-Non Commercial 4.0 International License subject to proper citation to the publication source of the work.

Disclaimer: The scholarly papers as reviewed and published by the Institute of Research Advances (IRA) are the views and opinions of their respective authors and are not the views or opinions of the IRA. The IRA disclaims of any harm or loss caused due to the published content to any party.

Institute of Research Advances is an institutional publisher member of Publishers Inter Linking Association Inc. (PILA-CrossRef), USA. The institute is an institutional signatory to the Budapest Open Access Initiative, Hungary advocating the open access of scientific and scholarly knowledge. The Institute is a registered content provider under Open Access Initiative Protocol for Metadata Harvesting (OAI-PMH).

The journal is indexed \& included in CAS Source Index of Chemical Abstracts Service of American Chemical Society (USA), WorldCat Discovery Service (USA), CrossRef Metadata Search (USA), WorldCat (USA), OCLC (USA), Open J-Gate (India), EZB (Germany) Scilit (Switzerland), Airiti (China), Bielefeld Academic Search Engine (BASE) of Bielefeld University, Germany, PKP Index of Simon Fraser University, Canada. 


\section{INTRODUCTION}

While it is certain that various veterinary drugs used for the prevention and treatment of livestock animal diseases contribute to the stable production of animal products in recent years, on the other hand, the overuse or misuse of these drugs is of great concern because it can result in their presence in animal-derived foods for human consumption. To assure the safety of animal-derived foods for the consumer, Codex Aliamentarius sets maximum residue limits (MRLs) for veterinary drugs [1]. Because determinations for veterinary drugs in the animal-derived foods are therefore an important specific activity to guarantee food safety, the validated analytical method for the determining target drugs are presently required.

In answer to the present expansion and diversification in the international animal product trade, the development of international harmonized analytical methods (= universal standard methods) to determine veterinary drug residues in animal products is essential to guarantee equitable international trade in these foods and ensure food safety for consumers. Without regard for industrial nations and developing countries, the optimal harmonized analytical method for residue monitoring in foods must be quick, easy, reliable, inexpensive, and capable of quantifying residues at concentrations less than the target drug's MRL in animal products and must cause no harm to the environment and analyst.

Although several methods have been described in the literature for quantifying veterinary drugs in foods [2-5], these methods have three crucial drawbacks as follows: 1) the sample preparation operations are complicated and labor intensive, which are time-and cost-consuming, do not permit the determination of large number of samples, and can give low reproducibility; 2) organic solvents are used as extraction solvents, purification eluent, and/or as LC mobile phases without fail -Risk associated with these solvents extend beyond direct implications for the health of humans and wildlife to affect our environment and the ecosystem in which we all reside. Eliminating the use of organic solvents is an important goal in terms of environmental conservation, human health and the economy[6]; 3)the detections/identifications are based on LC-MS or -MS/MS - The facilities that LC-MS/MS system is available are limited to part of industrial nations because these are hugely expensive, and the methodologies use complex and specific. These are unavailable in a lot of laboratories for routine analysis, particularly in developing countries. No optimal method that satisfies the aforementioned requirements has yet been identified.

As an optimal technique that can be recommended as an international harmonized analytical method for the routine residue monitoring in animal-derived foods, this paper describes a quick, easy, and small-scale sample preparation followed by an isocratic water mobile phase HPLC method for determining sulfadimidine (SDD) in cow's milk under no-use organic solvent conditions. The SDD selected here is one of the most frequently used veterinary drugs worldwide, and has only the Codex's MRL $(0.0025 \mu \mathrm{g} / \mathrm{mL}$ for SDD in milk) set for several kinds of sulfonamides[1].Cow's milk contains a good balance of protein, fat, and carbohydrate, is an indispensable food because it is inexpensive and readily available.

\section{Materials and Methods}

\section{Reagents and apparatus}

All chemicals including sulfadimidine (SDD) standard were purchased from Wako Pure Chem. Ltd. (Osaka, Japan). Distilled waters were of HPLC grade.

The following apparatuses were used in the sample preparation: handheld ultrasonic-homogenizer (model HOM-100, 2 mm ID probe, Iwaki Glass Co., Ltd., Funabashi, Japan); micro-centrifuge (Biofuge ${ }^{\circledR}$ fresco, Kendo Lab. Products, Hanau, Germany); MonoTip ${ }^{\circledR} \mathrm{C} 18$ pipette tip (packed with silica monolith that consists of continuous through-pores and octadecyl bonding); sample throughput volume $\leq 200 \mu \mathrm{L}$; through-pore diameter of 10 - $20 \mu \mathrm{m}$; meso-pore of $20 \mathrm{~nm}$; surface area of $200 \mathrm{~m}^{2} / \mathrm{g}$ (GL Sciences, Inc., Tokyo, Japan).

The HPLC system, used for method development, included a model PU-980 pump and DG-980-50-degasser (Jasco Corp., Tokyo, Japan) equipped with a model CTO-10AS vpcolumn oven (Shimadzu Scientific Instruments, Kyoto, Japan), as well as a model SPD-M10A $V P$ diode-array detector (DAD) (Shimadzu). The following six types of $\mathrm{C} 1$ or $\mathrm{C} 4$ non-polar sorbent (the highly purified silica-based) columns $\left(5 \mu \mathrm{m} \mathrm{d}_{P} ; 4.6 \mathrm{~mm}\right.$ i.d.; $150 \mathrm{~mm}$ length) for HPLC analysis were used: Inertsil ${ }^{\circledR} \mathrm{WP} 300 \mathrm{C} 4$ (GL Sciences Inc., Tokyo, Japan); Inertsil ${ }^{\mathbb{R}}$ TMS (GL Sci.); Spherisorb ${ }^{\circledR} \mathrm{C} 1$ (Waters Corporation, MA, USA); Wakopak ${ }^{\circledR}$ Wakosil 5TMS (Wako Pure Chemical Industries, Ltd., Osaka, Japan); Wakopak ${ }^{\circledR}$ Wakosil 5C4-200 (Wako); ZORBAX ${ }^{\circledR}$ TMS (Agilent Technologies, CA, USA). Table 1 lists the particle physical/chemical specifications. 
Table 1: Physical and chemical specifications of particles packed into the $\mathrm{C} 1$ and $\mathrm{C} 4$ columns ${ }^{\mathrm{a}}$ used and chromatographic sulfadimidine (SDD) separation obtained under the HPLC conditions examined ${ }^{\text {b }}$

\begin{tabular}{|c|c|c|c|c|c|c|c|c|}
\hline \multicolumn{3}{|r|}{ Column } & \multirow{2}{*}{$\begin{array}{c}\text { Pore diameter } \\
\text { (nm) }\end{array}$} & \multirow{2}{*}{$\begin{array}{l}\text { Pore volume } \\
\qquad(\mathrm{mL} / \mathrm{g})\end{array}$} & \multirow{2}{*}{$\begin{array}{c}\text { Surface area } \\
\left(\mathrm{m}^{2} / \mathrm{g}\right)\end{array}$} & \multirow{2}{*}{$\begin{array}{c}\text { Carbon content } \\
(\%)\end{array}$} & \multicolumn{2}{|c|}{ HPLC taeget compound } \\
\hline & Silica type & Trade name & & & & & Separation & Peak form \\
\hline (A) & $\mathrm{C} 1$ & Inertsil TMS & 10 & 1.05 & 150 & 3.5 & $\mathrm{NE}^{\mathrm{c}}$ & - \\
\hline (B) & $\mathrm{C} 4$ & Inertsil WP300 C4 & 30 & 1.05 & 450 & 3 & Separated & Symmentrical/Sharp \\
\hline (C) & $\mathrm{C} 1$ & Spherisorb C1 & 8 & $\mathrm{nd}^{\mathrm{d}}$ & 220 & 2.2 & $\mathrm{NR}^{\mathrm{e}}$ & - \\
\hline (D) & $\mathrm{C} 1$ & Wakopak Wakosil 5TMS & 12 & 1 & 300 & 4 & NE & - \\
\hline (E) & $\mathrm{C} 4$ & Wakopak Wakosil 5C4-200 & 20 & 1 & 200 & 5 & $\mathrm{NE}$ & - \\
\hline (F) & $\mathrm{C} 1$ & ZORBAX TMS & 7 & nd & 300 & 4 & $\mathrm{NE}$ & - \\
\hline
\end{tabular}

${ }^{\mathrm{a}} \mathrm{d}_{\mathrm{p}}=5 \mu \mathrm{m}$; i.d. $=4.6 \mathrm{~mm}$; length $=150 \mathrm{~mm}$

${ }^{\mathrm{b}}$ Isocratic mobile phase of water; flow-rates $\geq 0.5 \mathrm{~mL} / \mathrm{min}$; column temperatures $\geq 25^{\circ} \mathrm{C}$; HPLC retention times $\leq 10 \mathrm{~min}$

${ }^{\mathrm{c}}$ No SDD was eluted.

${ }^{\mathrm{d}}$ No data.

${ }^{\mathrm{e}}$ No SDD retained.

\section{Pipette tip operating procedure}

After attaching a MonoTip C18 pipette tip to a micro pipette $(20-200 \mu \mathrm{L}$ volume type), preconditioning of the tip was carried out by drawing and ejecting (to waste) $100 \mu \mathrm{L}$ of distilled water to reduce background noise. A $100 \mu \mathrm{L}$ aliquot of the sample was drew into the conditioned MonoTip C18 tip, and ejected back into another sample tube. This series of in and out operations was defined as one pipetting operation in this study.

\section{HPLC operating conditions}

The analytical column was anInertsil@ WP300 C4 $(150 \times 4.6 \mathrm{~mm}, 5 \mu \mathrm{m})$ column using an isocratic mobile phase of water at a flow rate of $1.0 \mathrm{~mL} / \mathrm{min}$ at $35^{\circ} \mathrm{C}$. DAD was operated at $190-350 \mathrm{~nm}$ : the monitoring wavelength was adjusted to $258 \mathrm{~nm}$ which represent maximum for SDD. The injection volumes were $10-20$ $\mu \mathrm{L}$.

\section{Preparation of stock standards and working solutions}

Stock standard solution of SDD was prepared by dissolving SDD in water followed by water to a concentration of $50 \mu \mathrm{g} / \mathrm{mL}$. This solution was stored at $-20^{\circ} \mathrm{C}$. Working standard solutions of this compound were freshly prepared by suitably diluting the stock solutions with water on the day of the analysis.

\section{Preparation of calibration standards and quality control samples}

For method validation studies, calibration standards and quality control samples (QCs), terms defined in the FDA guideline [7], were prepared by spiking appropriate aliquots of the mixed standard solution in blank milk samples. Calibration standards were used to construct calibration curves from which the concentrations of analyte in unknown monitoring samples are determined practically. QCs used to evaluate the performance of the proposed method. In this study, the standards were prepared in the range of $0.05,0.1,0.25,0.35,0.5$, and $1.0 \mu \mathrm{g} / \mathrm{mL}$ for analyte. Three QC levels (For both analytes, QC1 $=0.05 \mu \mathrm{g} / \mathrm{mL} ; \mathrm{QC} 2=0.1 \mu \mathrm{g} / \mathrm{mL} ; \mathrm{QC} 3=0.35$ $\mu \mathrm{g} / \mathrm{mL}$ ) were prepared.

\section{Sample preparation}

An accurate $100 \mu \mathrm{Lmilk}$ sample was taken into a $1.5 \mathrm{~mL}$ micro-centrifuge tube and homogenized with $600 \mu \mathrm{L}$ of water with a handheld ultrasonic-homogenizer for $30 \mathrm{~s}$. After being homogenized, the capped tube was centrifuged at $10,000 \mathrm{~g}$ for $5 \mathrm{~min}$. A $100 \mu \mathrm{L}$ aliquot of supernatant liquid was aspirated into the conditioned MonoTip C18 pipette tip and dispensed back into the sample tube. The eluate was injected into the HPLC system.

\section{Method validation}

The performance of the developed method was validated in terms of many parameters from the international guidelines for bio-analytical procedure [8-11]. 


\section{RESULTS and DISCUSSION}

\section{Sample preparation}

The advantage of the present procedure is that SDD in milk is pretreated quickly, economically, and environment-friendly on small-scale, requiring only water as the analytical reagent. The ultrasonic-homogenization enabled the satisfactory extraction of SDD from a milk sample of $0.1 \mathrm{~mL}$ with water of $0.6 \mathrm{~mL}$ without bumping. The extract from milk did not form an emulsion that would hinder SDD recoveries. The extract obtained was easily purified by a MonoTip ${ }^{\circledR} \mathrm{C} 18$ pipette tip, which was performed by one pipetting operation with water eluent of $0.1 \mathrm{~mL}$. The time required for the sample preparation of a single milk sample, including the centrifugation for $5 \mathrm{~min}$, was $<7 \mathrm{~min}$. The quick and easy procedure resulted in high recovery and reproducibility with great saving time and cost. The resulting extract was free from interference, as can be seen in HPLC traces of blank (Fig. 1b) and spiked milk sample (Fig. 1a).These findings demonstrate that the extraction and purification worked well.

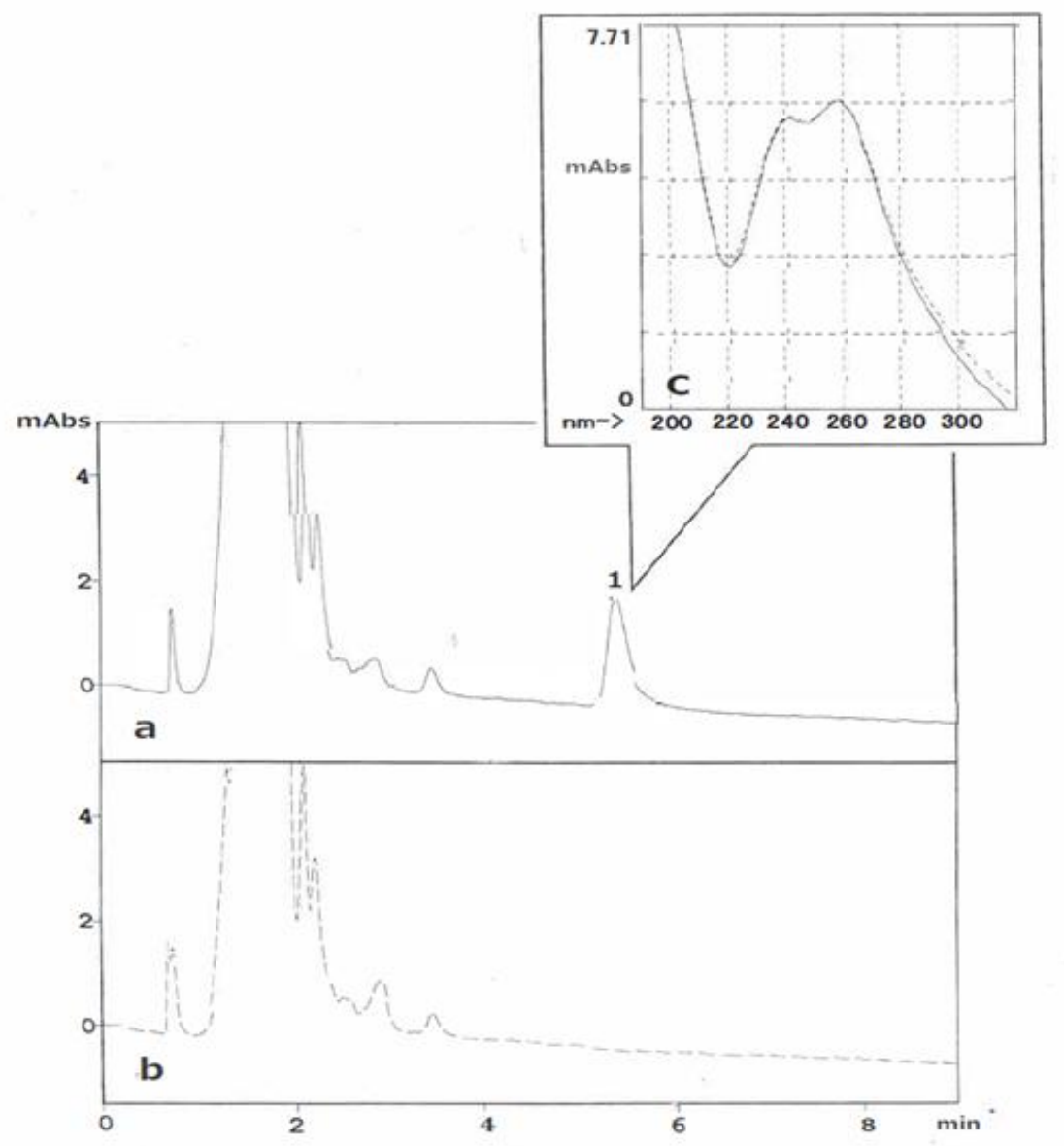

Figure 1: Chromatograms obtained from the present HPLC system for milk samples (a,b) and typical absorption spectra for SDD (c).

a: Spiked $(0.35 \mu \mathrm{g} / \mathrm{mL}$ of SDD) milk sample; Peak $1=\operatorname{SDD}$ (Retention time $=5.36 \mathrm{~min})$.

b: Blank milk sample.

c: Absorption spectra of peak 1 (solid line) and SDD standard (dashed line), respectively.

\section{Optimal HPLC conditions}

In order to achieve the separation with a $100 \%$ water mobile phase optimize faster separation, the author tested six types of $\mathrm{C} 1$ or $\mathrm{C} 4$ columns. Table 1 lists physical and chemical specifications of particles packed into the columns. This study used water as the isocratic mobile phase and examined column temperatures $\geq 25^{\circ} \mathrm{C}$, HPLC flow rates $\geq 0.5 \mathrm{~mL} / \mathrm{min}$, and HPLC retention times $\leq 10 \mathrm{~min}$ : because the HPLC separations were performed serially, the time/run was critical for routine residue monitoring. The short run time not only 
increased sample throughout for analysis but also affected the method-development time. The six columns were compared regard to 1) the elution from columns; 2) the separation between SDD and its interfering peaks; 3) sharpness of peaks obtained upon injection of equal amounts. The resulting chromatographic separation and peak form profiles within the conditions ranges examined are also presented in Table 1.

The separation of SDD and interference peaks, a symmetrical peak, and a short retention time were achieved with Column (B) and using an isocratic water mobile phase with a follow rate of $1.0 \mathrm{~mL} / \mathrm{min}$ and a column temperature of $35^{\circ} \mathrm{C}$. Figure 1-a,b displays typical chromatograms for a spiked milk sample and for a blank milk sample obtained under the procedure developed here, with the DAD set at $258 \mathrm{~nm}$ (giving maximum absorption spectrum for SDD). The HPLC-DAD system achieved optimal separation in < 5.5 min without the need for a gradient system to improve the separation or pre-column washing after the analysis. This figure demonstrate that the present method can provide the quantification and identification of the analyte.

\section{Method validation}

Table 2: Method validation data

\begin{tabular}{|c|c|c|c|c|}
\hline \multicolumn{2}{|c|}{ Parameter } & Sulfadimidine (SDD) & Codex acceptance criterion $^{\mathrm{a}}$ & FDA recommendation $^{\mathrm{b}}$ \\
\hline \multicolumn{2}{|l|}{ Range $(\mu \mathrm{g} / \mathrm{mL})$} & $0.05-1$ & & \\
\hline \multicolumn{2}{|l|}{ Accuracy $^{\mathrm{d}}(\%)$} & 94.1 & $70-110$ & \\
\hline \multicolumn{2}{|l|}{$\operatorname{Precision}^{\mathrm{e}}(\%)$} & 3.2 & $\leq 20$ & \\
\hline \multirow{2}{*}{ System suitability ${ }^{\mathrm{h}}$} & Retention time & 0.21 & & $\leq 1$ \\
\hline & Peak area & 0.28 & & $\leq 1$ \\
\hline
\end{tabular}

${ }^{\mathrm{a}}[10,11]$.

${ }^{\mathrm{b}}$ Recommended data in the FDA guidelines [9].

${ }^{\mathrm{c}} \mathrm{r}$ is the correlation coefficient $(\mathrm{p}<0.01)$ for the calibration curve.

${ }^{\mathrm{d}}$ Average recoveries from 18 replicates (= six replicates at thee spiked levels: $0.05,0.1$, and $0.35 \mu \mathrm{g} / \mathrm{mL}$ for SDD).

${ }^{\mathrm{e}}$ Values are relative standard deviation (RSD, $\mathrm{n}=18$ ).

${ }^{\mathrm{f}}$ Quatitative limit as the concentration of analyte giving a signal-to-noise ratio $=10$.

${ }^{g}$ Maximum residue limit (MRL) for SDD in cow's milk (set by the Codex Alimentarius [1]).

${ }^{\mathrm{h}}$ Data as the relative standard deviations calculated for 10 replicate HPLC injections of the prepared eluate for a milk sample spiked with $\mathrm{SDD}(0.35 \mu \mathrm{g} / \mathrm{mL})$.

Table 2 summarizes the main method validation parameters. The quantitative limit in milk samples was 0.022 $\mu \mathrm{g} / \mathrm{mL}$ for SDD. The value is less than the MRL. The system-suitability evaluation is an essential parameter of HPLC determination, and it ascertains the strictness of the system used. The suitability was evaluated as the relative standard deviations of peak area and retention time calculated for 10 replicate injections of a spiked milk sample with SDD $(0.35 \mu \mathrm{g} / \mathrm{mL})$. The values were estimated to be $0.21 \%$ for retention time and $0.28 \%$ for peak area, respectively. Including this system-suitability, the linearity, accuracy, and precision are within the international acceptance criteria (Table 2) [9-11]). The other validation findings are as follows:

The application of the proposed procedure to 10 blank milk samples demonstrated that no interference peak was presented around the retention time for SDD in any of the sample examined.

The present HPLC-DAD system easily confirmed the peak identity of target compound. The analyte was identified in a milk sample by its retention time and absorption spectrum. For example, in Figure 1-c, the SDD spectra obtained from the milk sample was practically identical to that of the standard. Because of the complete separation of the analyte was achieved, trace-level DAD detection is possible. It is therefore instructive to demonstrate purification effectiveness of the sample preparation. The system did not require the use of MS or MS/MS, which is very expensive and is not widely available for routine work.

\section{Cost and time performances}

The total time and budget required for the analysis of a single sample were less than 12min and approximately $\$ 6.2$ (as of15November2017), respectively. For sequential analysis, a batch of 24 samples could be analyzed 
in less than $2.5 \mathrm{~h}$. These findings became term required for the routine assay. The short time and low-cost quantitative method increased the sample throughput for actual routine monitoring work.

\section{Application to real milk samples}

Twenty samples of commercial raw milk purchased from convenience stores in Osaka, Japan were analyzed using the present method. No samples contained detectable concentrations of SDD. All chromatograms were free from interferences.

\section{CONCLUSION}

A pipetting sample preparation with water eluent followed by an isocratic water mobile phase HPLC-DAD method for quantification of residual SDD in cow's milk has been successfully established. The method validation data were well within the international method acceptance criteria. The present procedure provided an easy-to-use, fast, and environment/analyst-friendly and resulted in high recovery and repeatability with considerable saving of analysis time/cost. In particular, the present technique may be proposed as an international harmonized method for routine residue monitoring SDD in cow's milk.

\section{REFERENCES}

[1] Codex alimentarius 2017. Codex Veterinary Drug Residue in Food Online Database. (Updated up July 2017).

[2] Wang, J., Leung, D., Chow, W., Chang, J., Wong, J.W. 2015. Development and Validation of a Multiclass Method for Analysis of Veterinary Drug Residues in Milk Using Ultrahigh Performance Liquid Chromatography Electrospray Ionization Quadrupole Orbitrap Mass Spectrometry. Journal of Agricultural and Food Chemistry, Vol. 63: 9175-9187.

[3] Masiá, A., Suarez-Verela, M.M., Liopis-Gonzalez, A., Picó, Y. 2016. Determination of pesticides and veterinary drug residues in food by liquid chromatography-mass spectrometry: A review. Analytica Chimica Acta, Vol. 936: 40-61.

[4] Saito-Shida, S., Sakai, T., Nemoto, S., Akiyama, H.2017. Quantitative analysis of veterinary drugs in bovine muscle and milk by liquid chromatography quadrupole time-of-flight mass spectrometry. Food Additives \& Contaminants: Part A, Vol. 34: 1153-1161.

[5] Clark, S.B., Storey, J.M., \& Turnipseed, S.B. 2017. Optimization and validation of multi-class, multi-residue LC-MS/MS screening and confirmation method for drug residues in milk. FDA-Laboratory Information Bulletins, \#4443, pp. 1-27.

[6] Anastas, P.T., Warner, J.C. 1998.Green Chemistry: Theory and Practice, Oxford University Press, Oxford, United Kingdom.

[7] FDA/CDER/CVM 2001. Guidelines for Industry - Bioanalytical Method Validation.

[8] ICH1994. ICH Harmonised Tripartite Guideline, Validation of Analytical Procedures: Text and Methodology Q2 (R1).

[9] FDA/CDER 1994. Reviewer Guide, Validation of Chromatographic Methods.

[10] Codex alimentarius 2001. CAC/GL 37-2001: Harmonized IUPAC Guidelines for the use of Recovery Information in Analytical Measurement.

[11] Codex alimentarius 2009. CAC/GL 71-2009: Guidelines for the Design and Implementation of National Regulatory Food Safety Assurance Programme Associated with the Use of Veterinary Drugs in Food Producing Animals. 